\title{
Global change and Antarctic terrestrial biodiversity
}

\author{
Ian D. Hogg • Diana H. Wall
}

Published online: 23 September 2011

(c) Springer-Verlag 2011

Over the past 50 years, portions of Antarctica and the sub-Antarctic islands have experienced some of the most rapid increases in mean air temperatures on Earth. For example, recent data released by NASA have shown that mean annual air temperatures over the Western Antarctic Ice Sheet (WAIS) have already increased by roughly $1^{\circ} \mathrm{C}$ and more than $2^{\circ} \mathrm{C}$ in the maritime Antarctic (e.g. Turner et al. 2005). Over the same period, introductions of nonindigenous species have also continued to increase particularly in the sub-Antarctic islands (Frenot et al. 2005). While ongoing debate, often politically motivated, continues to dominate discussion of climate change and its impacts, it is virtually certain that temperature increases and species' introductions will intensify and continue to influence Antarctic terrestrial ecosystems over the next 50 years. Other human activities such as increasing numbers of tourists and scientists will affect the present terrestrial systems as well as those newly revealed as a result of glacial melt. Collectively, these changes will influence Antarctica's biodiversity and ecosystem functioning as well as the corresponding feedbacks to glaciers, freshwater systems and the atmosphere. Thus, it is urgent that we develop a strong knowledge base for Antarctic terrestrial ecosystems and use this to identify ecosystem change (NAS 2011).

\footnotetext{
I. D. Hogg $(\bowtie)$

Department of Biological Sciences, University of Waikato, Private Bag 3105, Hamilton 3240, New Zealand

e-mail: hogg@waikato.ac.nz

D. H. Wall

Department of Biology and Natural Resource Ecology Laboratory, Colorado State University, Fort Collins, CO 80523, USA
}

In order to advance our current state of knowledge, the Scientific Committee for Antarctic Research (SCAR), through its life sciences programme Evolution and Biodiversity in the Antarctic (EBA, http://www.eba.aq), has encouraged multidisciplinary and multinational research efforts. As part of this initiative, a special session on Global Tipping Points, "Global Change and Antarctic Terrestrial Biodiversity", was convened at the 2010 SCAR Open Science Conference held in Buenos Aires (August 3-6, 2010).

This special issue of Polar Biology and the articles that follow were based on this special session and were solicited to cover a range of topics, viewpoints and contributing countries. We have assembled eight such manuscripts that cover microbiological, botanical and zoological components as well as representing studies from continental, peninsular and sub-Antarctic island locations. This special issue also provides a useful complement to a previous special issue of Polar Biology devoted to polar marine and freshwater ecosystems (Agustí et al. 2010).

The lead article by Convey (2011, this special issue) provides an overview of the Antarctic terrestrial environment and its biodiversity. It then examines the range of environmental changes as well as direct and indirect human activities that are likely to impact on this unique environment. The final section is future-focused, outlining research needs as well as the research programmes and initiatives, past and present, which aim to address these issues. It ends with a plea for the urgent need to plan and properly fund, at national and international levels, appropriate monitoring, manipulations and modelling approaches across the range of terrestrial environments found within the Antarctic (Wall et al. 2011).

Green et al. (2011, this special issue) provide a detailed perspective on the consequences of increased temperatures for Antarctica's vegetation. Using regression analyses 
based on a range of data and focussing primarily on lichen and moss taxa, they suggest that two main zones can be identified: a micro-environmental zone (south of $72^{\circ} \mathrm{S}$ ) and a macro-environmental zone (north of $72^{\circ} \mathrm{S}$ ). Within the macro-environmental zone, the distribution of taxa is driven by large-scale gradients in temperature, such that taxon richness and density decrease with increasing latitude. In contrast, for the micro-environmental zone, the distribution of taxa is driven by unique occurrences of abiotic factors such as temperature, moisture and shelter. Here, the diversity of taxa shows no meaningful relationship with latitude. They conclude with a series of predictions on the consequences of increasing temperature. For example, change will be more pronounced in the macro-environmental zone with a predicted increase of $10 \%$ of total species present for every $1^{\circ} \mathrm{C}$ increase in mean air temperatures. There will also be a concomitant southward movement of the boundary between macro- and micro-environmental zones.

Khan et al. (2011, this special issue) provide new data on the little-known hypolithic communities of Antarctica. With a focus on the archaeal, bacterial and eukaryotic taxa from the Dry Valleys of Victoria Land, they demonstrate the hypolithic microbial communities are distinct from surrounding open soil communities and that they also show differences in community structure even within hypolithic communities. This demonstrates a considerably greater level of spatial variability than previously thought. However, they conclude that further work is required to understand the factors responsible for community structure and development.

Farrell et al. (2011, this special issue) provide an overview of fungi. Initially, this work was focused on the degradation of historic huts of the 'heroic' era and the influences of air temperatures and humidity. Ultimately, their work was extended to include taxa from more pristine habitats including from soils in surrounding undisturbed areas. Surprisingly, there was considerable overlap of fungal species (e.g. Cadophora spp.) between the historic and pristine sites. However, there was also considerable variability found within habitats (e.g. within historic huts). Most taxa were cold-tolerant but also capable of growing at warmer temperatures. Accordingly, increases in air temperature are unlikely to adversely affect Antarctic fungal taxa or limit their degradative processes.

Torres-Mellado et al. (2011, this special issue) look at changes in populations of higher plants, Deschampsia antarctica and Colobanthus quitensis, along a transect on the Antarctic Peninsula and surrounding regions. Despite increases in air temperatures in the region and measurable increases in vegetation cover at several sites, they did not find a direct north-south relationship. They conclude that other biotic (e.g. presence of moss) and abiotic (e.g. wind, water availability) factors are also responsible for the observed patterns of expansion and colonisation of these plants within their study area.

The Iles Kerguelen have among the highest levels of nonindigenous species' introductions, including rabbit. Robin et al. (2011, this special issue), using remote sensing, look at recent changes in plant communities on five small islands in the Kerguelen Archipelago. On three islands, rabbits had been eradicated; they remained on one and had never been on the other. These latter two islands served as "control" sites and collectively allowed an evaluation of changes occurring as a consequence of recent climate changes as well as providing a baseline for future monitoring. In all cases, vegetation cover was observed to decrease.

Focussing on the zoological components, Nielsen et al. (2011, this special issue) provide an overview of Antarctic nematode communities and ecological consequences of climate changes. They detail the direct and indirect consequences of climate changes, as well as the observed and predicted responses of nematodes to these changes. They conclude that there is unlikely to be a uniform response to future changes and that responses are likely to be locationspecific. For example, some areas may experience density and diversity decreases, whereas others may show the opposite pattern.

Similarly, McGaughran et al. (2011, this special issue) look at the physiological and ecological responses of increased temperatures on the larger terrestrial invertebrates by providing a springtail (Collembola) perspective. Specifically, they provide data on the dispersal and metabolic rates of Gomphiocephalus hodgsoni populations from the Ross Sea Region of Antarctica. They conclude that springtails, and likely other invertebrates such as nematodes, have maintained flexible life-history strategies that are partially uncoupled from their local thermal microhabitats.

A recurring theme in these studies is the considerable variability that exists within Antarctic terrestrial ecosystems even on relatively small spatial scales (e.g. Khan et al. 2011; Nielsen et al. 2011; McGaughran et al. 2011). Accordingly, there is unlikely to be a typical response to increasing temperatures, and both negative and positive responses are likely. Unfortunately, this makes predicting the consequences of climate changes even more problematic and the overall response of the systems somewhat uncertain. It is timely, then, that there is growing impetus from the scientific community and others to secure data on the variation in potential responses to climate change in Antarctica by implementing a coordinated long-term observation network (Wall et al. 2011). These data can then be used in modelling to refine predictions of how changes in multiple Antarctic ecosystems will affect Antarctica and ultimately the rest of the planet.

All contributions were reviewed by a minimum of two international referees and followed the normal Polar 
Biology editorial policy. We hope that this special issue will be a catalyst for further work, particularly as a legacy for the EBA programme as it draws to a close in 2013.

Acknowledgments We are grateful to Dieter Piepenburg, Editor in Chief, for the opportunity to assemble this special issue of Polar Biology. The Faculty of Science and Engineering, University of Waikato, provided Strategic Initiative Funds (SIF) to IH to attend the Open Science Conference in Buenos Aires. These contributions are an output of the Evolution and Biodiversity in Antarctica (EBA) programme under the auspices of the Scientific Committee on Antarctic Research (SCAR).

\section{References}

Agustí S, Sejr MK, Duarte DM (2010) Impacts of climate warming on polar marine and freshwater ecosystems. Polar Biol 33:15951598

Convey P (2011) Antarctic terrestrial biodiversity in a changing world. Polar Biol. doi:10.1007/s00300-011-1068-0

Farrell RL, Arenz BE, Duncan SM, Held, BW, Jurgens JA, Blanchette RA (2011) Introduced and indigenous fungi of the Ross Island historic huts and pristine areas of Antarctica. Polar Biol. doi: 10.1007/s00300-011-1060-8

Frenot Y, Chown SL, Whinam J, Selkirk PM, Convey P, Skotnicki M, Bergstrom DM (2005) Biological invasions in the Antarctic: extent, impacts and implications. Biol Rev 80:45-72

Green TGA, Sancho LG, Pintado A, Schroeter B (2011) Functional and spatial pressures on terrestrial vegetation in Antarctica forced by global warming. Polar Biol. doi:10.1007/s00300011-1058-2

Khan N, TuYn M, StaVord W, Cary C, Lacap DC, Pointing SB, Cowan D (2011) Hypolithic microbial communities of quartz rocks from Miers Valley, McMurdo Dry Valleys, Antarctica. Polar Biol. doi:10.1007/s00300-011-1061-7

McGaughran A, Hogg ID, Convey P (2011) Extended ecophysiological analysis of Gomphiocephalus hodgsoni (Collembola): flexibility in life history strategy and population response. Polar Biol. doi:10.1007/s00300-011-1001-6

NAS (2011) Future science opportunities in Antarctica and the Southern Ocean (report in brief). National Academy of Sciences http://wwwdels.nas.edu/prb. Accessed 10 Sept 2011

Nielsen UN, Wall DH, Adams BJ, Virginia RA (2011) Antarctic nematode communities: observed and predicted responses to climate change. Polar Biol. doi:10.1007/s00300-011-1021-2

Robin M, Chapuis J-L, Lebouvier M (2011) Remote sensing of vegetation cover change in islands of the Kerguelen archipelago. Polar Biol. doi:10.1007/s00300-011-1069-Z

Torres-Melado GA, Jaña R, Casanova-Katny MA (2011) Antarctic hairgrass expansion in the South Shetland Archipelago and Antarctic Peninsula revisited. Polar Biol. doi:10.1007/s00300011-1099-6

Turner J, Colwell SR, Marshall GJ, Lachlan-Cope TA, Carleton AM, Jones PD, Lagun V, Reid PA, Iagovkina S (2005) Antarctic climate change during the last 50 years. Int $\mathrm{J}$ Climatol 25:279-294

Wall DH, Lyons WB, Convey P, Howard-Williams C, Quesada A, Vincent WF (2011) Long term ecosystem networks to record change: an international imperative. Antarct Sci 23:209 